\title{
MAXIMISING THE EFFECTIVENESS OF INSECTICIDES TO CONTROL MEALYBUGS IN VINEYARDS
}

\author{
P.L. LO, V.A. BELL and J.T.S. WALKER \\ The New Zealand Institute for Plant \& Food Research Limited, Private Bag \\ 1401, Havelock North, Hastings 4157, New Zealand \\ Corresponding author: plo@hortresearch.co.nz
}

\begin{abstract}
Mealybugs (Hemiptera: Pseudococcidae) are the most important insect pests in New Zealand vineyards because they vector grapevine leafroll virus, which seriously debilitates vines and reduces wine quality. A field trial was conducted on a commercial vineyard using the insecticides prothiofos (Tokuthion ${ }^{\circledR}$ ) and buprofezin (Applaud ${ }^{\mathrm{TM}}$ ). Factors tested were the timing and number of applications, water rate $(250,500$ or 1000 litres/ha) and inclusion of an alkylsilicone or organosilicone spreader-type adjuvant. Prothiofos was applied in late September (late dormant), while buprofezin was sprayed at late dormant, mid October and late November (pre-flowering). The best treatments for reducing mealybug numbers and proportion of infested leaves were prothiofos at late dormant and two later applications of buprofezin. Two applications of buprofezin were more effective than one, more than halving the number of mealybugs. A water rate of 500 litres/ha was equally as effective as 1000 litres/ha. None of the three adjuvants improved the efficacy of prothiofos or buprofezin. Keywords: mealybug, insecticides, efficacy, grape.
\end{abstract}

\section{INTRODUCTION}

Three cosmopolitan species of mealybug (Hemiptera: Pseudococcidae) infest grapevines in New Zealand (Charles 1993): citrophilus (Pseudococcus calceolariae), longtailed ( $P$. longispinus) and obscure $(P$. viburni). Severe infestations contaminate bunches and result in vines coated with sooty mould. But more importantly, all three species can transmit Grapevine leafroll-associated virus 3 (GLRaV-3) (Petersen \& Charles 1997; Golino et al. 2002). Because mealybugs are the main vector of this virus they are the principal insect pests of grapes in New Zealand.

Worldwide there are several grape diseases with similar symptoms of downward-rolled leaves. These are caused by a complex of viruses from the families Closteroviridae and Flexiviridae. In New Zealand, the most widespread of these viruses is GLRaV-3 (Petersen \& Jordan 1992), which belongs to the Closteroviridae in the genus Ampelovirus. Numerous studies have documented the detrimental effects of GLRaV-3 (see Charles et al. 2006 for a review). These effects include significant declines in yield, reduced sugar levels and changes in colour, as well as delayed ripening of berries. Both red and white grape varieties are affected, but the classic symptoms of rolled leaves and reddening of the inter-vein area are most evident in red varieties. In recent years in Hawke's Bay, whole blocks of vines including some that formerly produced premium wines have been pulled out, solely because GLRaV-3 infection had become rampant.

Mealybugs can move short distances by walking, disperse hundreds of metres as windblown crawlers, or be carried on vineyard machinery, thus spreading virus both within blocks and between vineyards. These means of dispersal are consistent with the pattern of virus-spread in a newly planted vineyard (J.G. Charles \& K.J. Froud, unpubl. data). GLRaV-3 was initially detected most frequently in vines bordering a severely infected block. Thereafter the virus spread primarily from localised points of infection 
along vine rows and to neighbouring vines on adjacent rows. In addition, vines further away from the main zone of infection became infected in a seemingly random pattern.

In order to manage GLRaV-3 it is imperative that mealybugs are controlled to extremely low levels. Vineyard managers currently adopt widely different mealybug insecticide programmes and have variable success controlling this pest. The objective of this research was to maximise the effectiveness of the two main insecticides used against mealybugs on grapevines. Factors examined were the timing and number of applications, water rate and inclusion of adjuvants that are designed to improve spray coverage.

\section{Trial design}

\section{MATERIALS AND METHODS}

The trial was conducted on Sauvignon Blanc vines at a commercial vineyard in Hawke's Bay during the 2005-06 season. Treatments were replicated six times in a randomised block design. Each plot was one row wide, $18 \mathrm{~m}$ long and comprised 10 vines. There were two unsprayed guard rows between treated rows.

Two insecticides, prothiofos (Tokuthion) and buprofezin (Buprofezin 25W), were applied by handgun with variations in timing, water rates and inclusion of adjuvants to give a total of 17 treatments (Fig. 1). Prothiofos was applied at $100 \mathrm{ml} / 100$ litres at the late dormant growth stage on 21 September at 500 and 1000 litres/ha. One prothiofos treatment included the alkylsilicone oil adjuvant Reach $(50 \mathrm{ml} / 100$ litres $)$, which acts to reduce the surface tension of oil, thereby increasing its spread.

\begin{tabular}{|c|c|c|c|c|c|c|c|c|c|c|c|c|c|c|c|c|c|c|c|}
\hline & \multicolumn{18}{|c|}{ Treatment } \\
\hline & & 1 & 2 & 3 & 4 & 5 & 6 & 7 & 8 & 9 & 10 & 11 & 12 & 13 & 14 & 15 & 16 & 17 & 18 \\
\hline prothiofos & $21 \mathrm{Sep}$ & & & & & & & & & & & & & & & & & & \\
\hline \multirow{3}{*}{ buprofezin } & $21 \mathrm{Sep}$ & & & & & & & & & & & & & & & & & & \\
\hline & 18 Oct & & & & & & & & & & & & & & & & & & \\
\hline & $24 \mathrm{Nov}$ & & & & & & & & & & & & & & & & & & \\
\hline \multirow{3}{*}{$\begin{array}{l}\text { Water rate } \\
\text { (litres/ha) }\end{array}$} & 250 & & & & & & & & & & & & & & & & & & \\
\hline & 500 & & & & & & & & & & & & & & & & & & \\
\hline & 1000 & & & & & & & & & & & & & & & & & & \\
\hline \multirow{3}{*}{ Adjuvant } & Reach & & & & & & & & & & & & & & & & & & \\
\hline & Du-Wett & & & & & & & & & & & & & & & & & & \\
\hline & Boost & & & & & & & & & & & & & & & & & & \\
\hline
\end{tabular}

\section{FIGURE 1: Trial treatments for mealybugs on grapevines including insecticide, time of application, water rate and inclusion of adjuvants as indicated by the shaded boxes.}

Buprofezin was tested in combination with prothiofos and alone in one or two-spray treatments. It was applied at three timings: late dormant, 4 weeks later when shoots were $10-15 \mathrm{~cm}$ long and finally at the start of flowering. The second application was initially applied on 13 October 2005 , but $38 \mathrm{~mm}$ of rain fell during the following 24 hours so these sprays were re-applied 5 days later. For the late dormant sprays, both insecticides were mixed with $1 \%$ mineral oil, which acts as an insecticide itself and as a carrier for the insecticide.

Buprofezin (100 g/100 litres) was sprayed at the same two water rates as prothiofos and at a concentrate rate (250 litres/ha) when applied with adjuvants. The concentrate applications were tested with one of two organosilicone adjuvants: Du-Wett $(60 \mathrm{ml} / 100$ litres $)$ or Boost Penetrant $(100 \mathrm{ml} / 100$ litres $)$. These adjuvants are socalled 'superspreaders' that improve spray coverage, while Boost also aids penetration into leaves. For treatments using the 250 litre water rate, the rate of buprofezin was increased to keep the amount of product applied per hectare the same as for the 500 litre water rate. 


\section{Assessments and analysis}

The effect of the treatments on mealybug abundance was assessed by randomly sampling 25 bunches per plot on 7 March 2006 and 25 leaves from the bunch zone on 12 April 2006. Only the middle eight vines of each plot were sampled, leaving the outer two vines as buffers. Leaves were picked and brought back to the laboratory for examination, while bunches were inspected in situ. Bunches were cut open where there was sign of mealybugs. The severity of mealybug infestations on both leaves and bunches was scored according to the following categories: $0=$ no mealybugs, $1=1-5$ mealybugs, $2=6-20$ mealybugs and 3=21-50 mealybugs. The total number of mealybugs present was not counted but estimated to be the midpoint of each category. The data were analysed by a Generalised Linear Model ANOVA (Genstat 9.1), with contrasts to compare groups of treatments.

\section{RESULTS}

Mealybug infestations were low, with an estimated 1.0 mealybug per leaf and 2.2 per bunch at harvest in untreated plots that contained an average of $21 \%$ of leaves and $25 \%$ of bunches infested with mealybugs. All insecticide treatments reduced the percentage of leaves and bunches infested by mealybugs compared with those on untreated vines, but numbers of mealybugs on treated bunches were not significantly different from those on untreated. $(\mathrm{P}=0.63)$. Further analyses were carried out on the leaf data only and are presented in Appendix 1.

\section{Insecticides}

There were almost twice as many infested leaves at harvest in plots sprayed at late dormant with buprofezin compared with prothiofos, but the difference was not significant (Fig. 2). Following the prothiofos spray with one or two applications of buprofezin did not improve control further on either leaves or bunches.

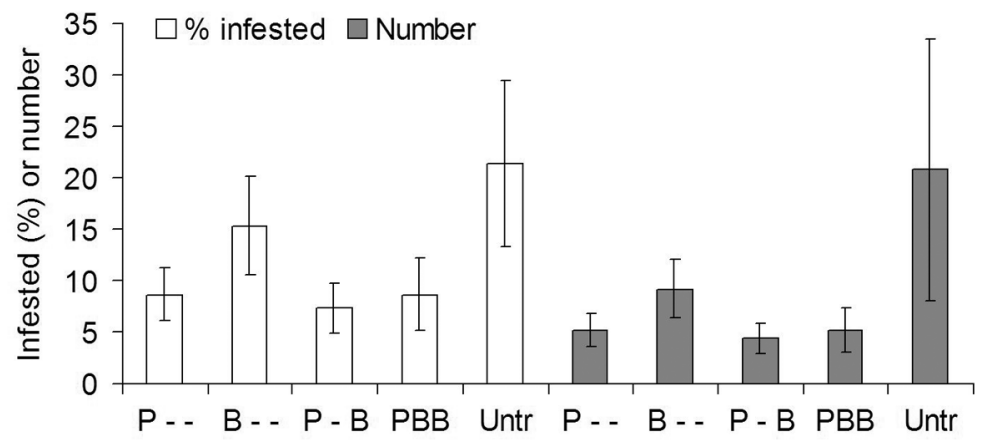

FIGURE 2: Comparison between prothiofos (P) and buprofezin (B) programmes at 500 litres/ha. Values are the mean $( \pm$ SEM) percentage of grape leaves at harvest infested by mealybugs and the estimated number of mealybugs per 25 leaves. The position of the product initial indicates when it was applied.

\section{Buprofezin timing}

Although there was no statistical difference between early (September-October) and late (October-November) buprofezin treatments, there was a trend for fewer mealybugs when treatments were applied later (Fig. 3). 


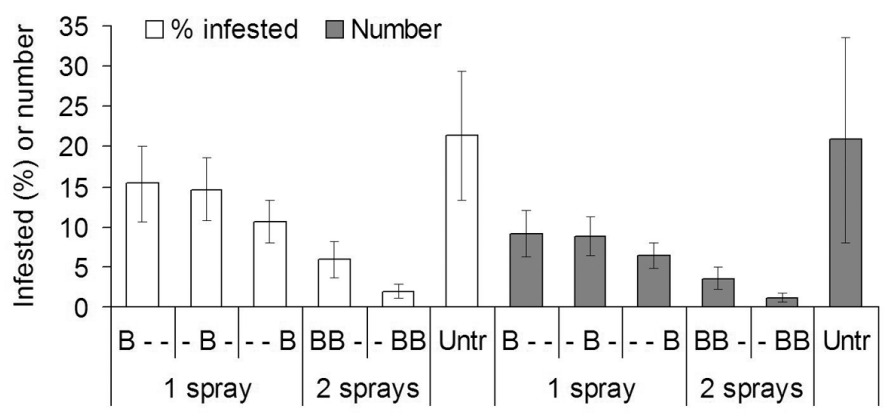

FIGURE 3: Effect of spray timing on efficacy of buprofezin (B) against mealybugs on grape leaves at harvest. Values are the mean $( \pm$ SEM) percentage of leaves infested with mealybugs and the estimated number of mealybugs per 25 leaves. All treatments were applied at 500 litres/ha and the position of the product initial indicates when it was applied.

\section{Number of buprofezin applications}

The incidence and number of mealybugs was significantly reduced in two-spray buprofezin treatments compared with a single application (Fig. 4). Typically one application reduced the incidence of mealybugs on leaves by a third and a second spray reduced this by a further third. The effect was greater on numbers of mealybugs, with $50 \%$ and $80 \%$ decreases on average, for one and two sprays respectively, compared with untreated vines. This effect occurred consistently at all three water rates when buprofezin was the only insecticide, but not when following a prothiofos application.

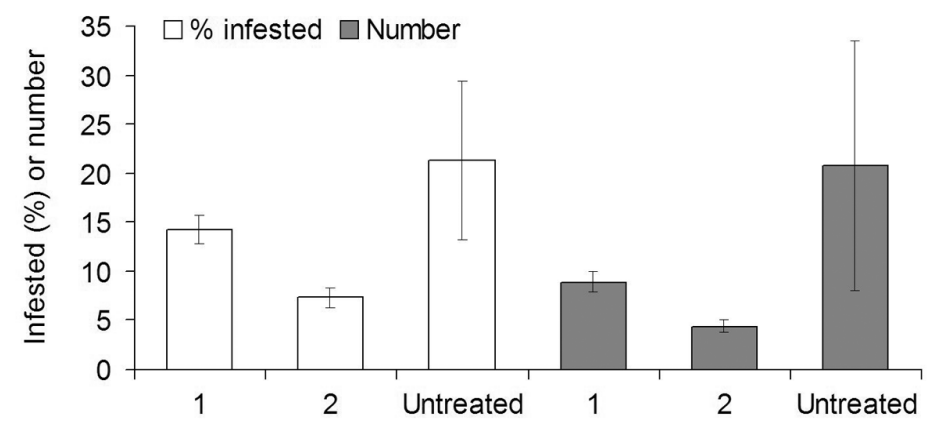

FIGURE 4: Comparison between the efficacy of one and two applications of buprofezin against mealybugs at 250,500 or 1000 litres/ha. Values are the mean $( \pm$ SEM) percentage of grape leaves at harvest infested with mealybugs and the estimated number of mealybugs per 25 leaves.

\section{Water rate}

The 500 litres/ha water rate was equally as effective as the high volume (1000 litres/ha) rate. The percentage of infested leaves was between 6-11\% for prothiofos and buprofezin at both water rates, while the estimated number of mealybugs per leaf was 4-7. Treatment differences between water rates for both insecticides were not significant (Appendix 1). 


\section{Adjuvants}

There was no advantage in terms of improved mealybug control from the addition of any of the three adjuvants (Appendix 1). Neither the percentage of infested leaves nor the estimated number of mealybugs per leaf was reduced compared with prothiofos and buprofezin applied on their own.

\section{DISCUSSION}

All treatments reduced mealybug infestations to varying extents, but differences between treatments were more subtle. Prothiofos appeared to give slightly better control of mealybugs on leaves than buprofezin applied at the same time, although statistically these treatments were similar. A previous trial conducted on Gewürztraminer vines found that at late dormant prothiofos was more effective than buprofezin (P.L. Lo, unpubl. data). It was surprising that a programme of prothiofos followed by one or two buprofezin sprays did not produce better control than prothiofos alone. The prothiofos application may have reduced numbers to such an extent that further sprays had a relatively small and undetectable effect on the mealybug population.

There was a definite improvement in mealybug control from a second application of buprofezin. This result occurred with early and late spray timings, at both 500 and 1000 litres/ha, and with both Du-Wett and Boost. It did not occur, however, after the prothiofos spray, perhaps for the reason suggested above.

Buprofezin can be applied to grapes up to the start of flowering, which typically occurs between mid November and mid December, depending on variety and region. This gives a narrow 2 month application window during the growing season. Although little difference was found in the efficacy of treatments based on the date of spraying, there was a trend for fewer mealybugs when buprofezin was applied later in both oneand two-spray programmes. Buprofezin inhibits chitin synthesis thereby disrupting moulting, so it is active against juvenile insects but is not toxic to adults (Ishaaya \& Horowitz 1998). Therefore it should be most effective against mealybugs in spring when the greatest proportion of the population is immature.

Prothiofos and buprofezin are contact insecticides that require good spray coverage to be effective. When designing the trial it was thought that a high water rate and the inclusion of adjuvants would enhance our ability to achieve better spray coverage of vines and consequently improved mealybug control. Neither of these factors, however, had a discernable effect on mealybug abundance. In the case of water rates, the handgun application at 500 litres/ha achieved good spray coverage, which was not improved by a doubling of the water volume. This may not necessarily be true for all commercial vineyard sprayers. These machines can vary widely in their spray coverage, especially when poorly configured (D.W.L. Manktelow, Applied Research and Technologies Ltd, pers. comm.). No measurements were made to see whether the adjuvants improved spray coverage, but in this trial none of the three products significantly reduced mealybug infestations compared with the spray treatments alone. There are other adjuvants available and these have reportedly reduced mealybug infestations in unpublished trials.

It is recommended that grapegrowers start the mealybug control season with a prothiofos and oil application at late dormant. Buprofezin, which has a different mode of action, should be saved for closer to flowering. For maximum control growers should use two buprofezin sprays, but if they decide on a single application, the best timing appears to be as late as possible before the pre-harvest interval limit of the start of flowering. With the handgun applications there was no advantage to having a water rate above 500 litres/ha or including spreader-type adjuvants for control of mealybugs. These results need to be confirmed for commercial spray equipment.

\section{ACKNOWLEDGEMENTS}

We thank New Zealand Winegrowers Inc. for funding this project and C.J. Pask Winery who provided the trial site. Sally Adamson and Tara Taylor assisted with the harvest assessments of leaves and bunches. 


\section{REFERENCES}

Charles JG 1993. A survey of mealybugs and their natural enemies in horticultural crops in North Island, New Zealand, with implications for biological control. Biocontrol Science and Technology 3: 405-418.

Charles JG, Cohen D, Walker JTS, Forgie SA, Bell VA, Breen KC 2006. A review of the ecology of Grapevine Leafroll associated Virus type 3 (GLRaV-3). New Zealand Plant Protection 59: 330-337.

Golino DA, Sim ST, Gill R, Rowhani A 2002. California mealybugs can spread grapevine leafroll disease. California Agriculture 56: 196-201.

Ishaaya I, Horowitz AR 1998. Insecticides with novel modes of action: an overview. In: Ishaaya I, Degheele D ed. Insecticides with Novel Modes of Action, Mechanism and Application. Springer, New York. Pp. 1-24.

Petersen CL, Charles JG 1997. Transmission of grapevine leafroll-associated closteroviruses by Pseudococcus longispinus and P. calceolariae. Plant Pathology 46: 509-515.

Petersen CL, Jordan D 1992. ELISA works well for the identification of leafroll. Proceedings of the New Zealand Grape and Wine Symposium: profit in the market, in the winery, in the vineyard. New Zealand Society for Viticulture and Oenology, Christchurch, New Zealand. Pp. 54-55.

\section{APPENDIX 1: $\quad$ Statistical analyses of the number of leaves infested (I) and estimated number of mealybugs per leaf $(\mathbf{N})$.}

\begin{tabular}{|c|c|c|c|c|c|}
\hline Question addressed & Result & Treatments & Data & $\mathrm{F}$ & $\mathrm{P}$ \\
\hline $\begin{array}{l}\text { Was prothiofos or buprofezin the best } \\
\text { insecticide at late dormant? }\end{array}$ & Equal & 1 vs 6 & $\begin{array}{l}\mathrm{I} \\
\mathrm{N}\end{array}$ & $\begin{array}{l}1.82 \\
1.05\end{array}$ & $\begin{array}{l}0.181 \\
0.308\end{array}$ \\
\hline $\begin{array}{l}\text { Did applying buprofezin after } \\
\text { prothiofos improve control? }\end{array}$ & No & 1 vs $4 \& 5$ & $\begin{array}{l}\mathrm{I} \\
\mathrm{N}\end{array}$ & $\begin{array}{l}0.02 \\
0.86\end{array}$ & $\begin{array}{l}0.877 \\
0.356\end{array}$ \\
\hline $\begin{array}{l}\text { What was the best timing of buprofezin } \\
\text { early or late? }\end{array}$ & Equal & 6,9 vs 8,10 & $\begin{array}{c}\mathrm{I} \\
\mathrm{N}\end{array}$ & $\begin{array}{l}1.54 \\
1.04\end{array}$ & $\begin{array}{l}0.218 \\
0.311\end{array}$ \\
\hline Were 2 buprofezin sprays better than 1 ? & Yes & $\begin{array}{c}4,6,7,8,11,14,16 \\
\text { Vs } \\
5,9,10,12,15,17\end{array}$ & $\begin{array}{l}\mathrm{I} \\
\mathrm{N}\end{array}$ & $\begin{array}{c}15.59 \\
9.71\end{array}$ & $\begin{array}{c}<0.001 \\
0.003\end{array}$ \\
\hline $\begin{array}{l}\text { Did a high water rate improve } \\
\text { insecticide efficacy } \\
\text { (a) prothiofos? }\end{array}$ & No & 1 vs 2 & $\begin{array}{l}\mathrm{I} \\
\mathrm{N}\end{array}$ & $\begin{array}{l}0.16 \\
0.15\end{array}$ & $\begin{array}{l}0.687 \\
0.702\end{array}$ \\
\hline (b) buprofezin? & No & 8,10 vs 11,12 & $\begin{array}{l}\mathrm{I} \\
\mathrm{N}\end{array}$ & $\begin{array}{l}0.65 \\
1.41\end{array}$ & $\begin{array}{l}0.422 \\
0.238\end{array}$ \\
\hline $\begin{array}{l}\text { Did adjuvants improve insecticide } \\
\text { efficacy? (a) Reach }\end{array}$ & No & 1 vs 3 & I & $\begin{array}{l}0.66 \\
0.19\end{array}$ & $\begin{array}{l}0.420 \\
0.668\end{array}$ \\
\hline (b) Du-Wett ${ }^{\mathrm{TM}}$ & No & 13 vs 14,15 & $\begin{array}{l}\mathrm{I} \\
\mathrm{N}\end{array}$ & $\begin{array}{l}0.49 \\
0.42\end{array}$ & $\begin{array}{l}0.485 \\
0.518\end{array}$ \\
\hline (c) Boost ${ }^{\circledR}$ & No & 13 vs 16,17 & $\begin{array}{l}\mathrm{I} \\
\mathrm{N}\end{array}$ & $\begin{array}{l}0.05 \\
1.32\end{array}$ & $\begin{array}{l}0.816 \\
0.254\end{array}$ \\
\hline
\end{tabular}

